\title{
Molecular Enrichment for Qualitative Molecular Pathogen Detection in Food
}

\author{
Patrick Mester $^{1} \cdot$ Martin Wagner $^{2} \cdot$ Peter Rossmanith $^{1,2}$
}

Received: 22 August 2017 / Accepted: 14 November 2017 / Published online: 4 December 2017

(C) The Author(s) 2017. This article is an open access publication

\begin{abstract}
Reliable detection of low levels of pathogenic microbial contaminants is one of the most important prerequisites to guarantee safe food production. In this work, the use of molecular enrichment (ME) subsequent to the sample preparation method Matrix-Lysis was evaluated solely for qualitative molecular pathogen detection from complex matrices. It could be successfully shown that the LOD of an all-molecular pathogen detection approach for food was effectively lowered by a factor of ten from $1.60 \times 10^{1} \mathrm{CFU} /$ $\mathrm{ml}$ to $1.60 \times 10^{0} \mathrm{CFU} / \mathrm{ml}$ due to $\mathrm{ME}$.
\end{abstract}

Keywords Molecular enrichment $\cdot \mathrm{qPCR} \cdot$ Pathogen detection $\cdot$ Matrix lysis $\cdot$ Foodborne pathogen

\section{Introduction}

In recent years, enormous research efforts have been continuously invested to improve existing methods for qualitative detection of bacterial pathogens in food processing environments (Dwivedi and Jaykus 2011; Nugen and Baeumner 2008; Witte et al. 2017). Polymerase chain reaction (PCR)-based methods are widely recognized to offer many advantages for food pathogen detection compared to culture-based methods. These advantages include ubiquity and reduced detection time, and these methods have been successfully adapted for quantification of foodborne pathogens (Dwivedi and Jaykus 2011). Nevertheless, a solely PCR-based approach for qualitative pathogen detection is hampered by the legal safety value of demonstrating absence within $25 \mathrm{~g}$ of food, which would require the ability to reliably detect as low as $1 \mathrm{CFU} / 25 \mathrm{~g}$ of food ample (European Commission 2005). "Conventional” PCR approaches to food pathogen detection, comprising sample preparation, DNA extraction/purification, and eventually PCR are

Peter Rossmanith

peter.rossmanith@vetmeduni.ac.at

1 Christian Doppler Laboratory for Monitoring of Microbial Contaminants, Department of Veterinary Public Health and Food Science, University of Veterinary Medicine, Veterinaerplatz 1 , 1210 Vienna, Austria

2 Institute of Milk Hygiene, Milk Technology and Food Science, Department of Veterinary Public Health and Food Science, University of Veterinary Medicine, Veterinärplatz 1, 1210 Vienna, Austria inherently not able to achieve such detection limits (Jaykus 2003; Stevens and Jaykus 2004). Resultantly, for qualitative PCR-based pathogen detection, a prior culture enrichment step is necessary, but it detracts from the advantages described above (Rossmanith et al. 2006; Mester et al. 2017).

Previously, a "conventional" PCR approach was combined with molecular enrichment (ME) by whole genome amplification (WGA) to achieve detection limits of 1-2 CFU/100 ml potable water, without the need for cultural enrichment (Maheux et al. 2011b; Maheux et al. 2011a). This complete molecular approach, called CRENAME, produced in $5 \mathrm{~h}$ equivalent results in terms of the limit of detection (LOD) and analytical specificity compared to the cultural gold standard. Introduction of ME into the analytical molecular detection chain for qualitative detection is particularly advantageous to facilitate detection in truly realtime. Further, an ME approach facilitates analysis of individual samples for the presence of different pathogens, even if they are present in low numbers, and potentially reduces the number of samples to be analyzed. However, so far it was unclear of a ME approach could also be applied to other foodstuff for which a prior sample preparation method is needed.

With one particular sample preparation method called "Matrix-Lysis", it is possible to process a large amount of various non-filterable complex matrices not processable with CRENAME, and the method has been successfully applied for quantification of different pathogens with detection limits of $\sim 10 \mathrm{CFU} / \mathrm{g}$ (Mester et al. 2010). Additionally, MatrixLysis effectively reduces the DNA background originating from the food matrices or dead bacteria, which facilitates application of a ME approach (Mayrl et al. 2009). In principle, 
the LOD and LOQ of an optimized and Poisson-validated qPCR assay is as little as one target per reaction. However, according to Poisson distribution, a minimum of three target copies are needed to obtain a $95 \%$ chance of including at least one target per reaction. This minimal LOD is only true if the optimized qPCR assay is able to detect one copy reliably, which has to be validated through a Poisson-based approach (Rossmanith and Wagner 2011). In this study, two previously published qPCR assays detecting Listeria monocytogenes and Salmonella enterica ser. Typhimurium were used, which have both been Poisson-validated (Rossmanith et al. 2006; Mann et al. 2013). In contrast to CRENAME, in this study, a different ME principle was chosen that is not based on WGA. Due to the non-specificity of WGA, it is known that high nontarget background DNA can introduce significant bias (Raghunathan et al. 2005; Fernando et al. 2010). Therefore, a pre-PCR approach for ME was chosen, where the same primer pairs of the subsequent detection reaction are used (Palka-Santini et al. 2009). Therefore, the aim of this study was to explore whether or not the inclusion of ME enhances a previously described sample preparation method, called Matrix-Lysis, for the simultaneous detection of two model pathogens.

\section{Material and Methods}

\section{Bacterial Strains and Culture Conditions}

L. monocytogenes EGDe (1/2a, internal number 2964) was used as a model organism for Gram-positive bacteria and as a DNA quantification standard for qPCR. Salmonella enterica serovar Typhimurium (NCTC 12023) was used as a model organism for Gram-negative bacteria and as a DNA quantification standard for qPCR. The bacteria were maintained at $80^{\circ} \mathrm{C}$ using MicroBankTM technology (Pro-Lab Diagnostics, Richmont Hill, Canada) and were part of the collection of bacterial strains at the Institute of Milk Hygiene, Milk Technology, and Food Science, University of Veterinary Medicine, Vienna, Austria. All bacterial strains were grown overnight in tryptone soya broth with $0.6 \%(w / v)$ yeast extract (TSB-Y; Oxoid, Hampshire, United Kingdom) at $37{ }^{\circ} \mathrm{C}$. Enumeration of bacterial suspensions was performed using the plate count method.

\section{Inoculation of Foods}

For artificial contamination of food, $1 \mathrm{ml}$ of the respective bacterial overnight culture was transferred to $8 \mathrm{ml}$ of fresh medium and incubated at $37{ }^{\circ} \mathrm{C}$ for $3 \mathrm{~h}$ to obtain a maximum of viable cells in the logarithmic growth phase. Subsequently, $100 \mu \mathrm{l}$ of the appropriate dilutions in PBS were added to each $12.5 \mathrm{ml}$ sample. The plate count method and tryptone soya agar plates supplemented with $0.6 \%(w / v)$ yeast extract (TSAY; Oxoid, Hampshire, United Kingdom) were used for quantification of all inocula. The agar plates were incubated at the respective growth temperature of $37{ }^{\circ} \mathrm{C}$ for $24 \mathrm{~h}$. Ultra-high temperature (UHT) milk samples were purchased from a local supermarket. Prior to the artificial contamination experiments, all samples were tested for the presence for $L$. monocytogenes and Salmonella enterica ser. Typhimurium, using the MatrixLysis protocol and respective real-time PCR assays and plating methods as described below, and only negative samples, were used for further testing.

\section{Real-Time Quantitative PCR and DNA Extraction}

qPCR detection of $L$. monocytogenes was performed by targeting a 274-bp fragment of the prfA gene, according to a previously published format (Rossmanith et al. 2006). Salmonella enterica ser. Typhimurium was detected by targeting an 85-bp fragment of the fimA gene, according to a previously published format (Mann et al. 2013). qPCR was performed in an Mx3000p real-time PCR thermocycler (Stratagene, La Jolla, CA, USA). For both assays, the final $25 \mu \mathrm{l}$ volume contained $5 \mu \mathrm{l}$ of DNA template. For the $\operatorname{fimA}$ assay, a qPCR temperature profile with an initial denaturation step at $94{ }^{\circ} \mathrm{C}$ for $2 \mathrm{~min}$ and an amplification protocol with 45 cycles $\left(94{ }^{\circ} \mathrm{C}\right.$ for $30 \mathrm{~s}$ and $60^{\circ} \mathrm{C}$ for $\left.1 \mathrm{~min}\right)$ were used. For the prfA assay, a qPCR temperature profile with an initial denaturation step at $94{ }^{\circ} \mathrm{C}$ for $2 \mathrm{~min}$ and an amplification protocol with 45 cycles $\left(94{ }^{\circ} \mathrm{C}\right.$ for $15 \mathrm{~s}$ and $64{ }^{\circ} \mathrm{C}$ for $\left.1 \mathrm{~min}\right)$ were used. All primers and probes used in this study are listed in Table 1.

DNA isolation was performed using the NucleoSpin $₫$ tissue kit (Machery-Nagel, Düren, Germany) and the support protocol for Gram-positive bacteria. The final step of the protocol was modified, and thereby two times $50 \mu \mathrm{l}$ of double distilled water were used to elute the DNA from the column.

\section{Matrix-Lysis Procedure}

Matrix-Lysis was performed as previously published, but with an adapted lysis buffer system consisting of $1 \mathrm{M} \mathrm{MgCl}_{2}+$ $50 \mathrm{mM}$ Tricine pH 7.6 (Mester et al. 2010; Mester et al. 2014). For each sample, $12.5 \mathrm{ml}$ of UHT milk foodstuff were mixed with $10 \mathrm{ml}$ lysis buffer $\left(1 \mathrm{M} \mathrm{MgCl}_{2}\right.$ and $50 \mathrm{mM}$ Tricine $\mathrm{pH}$ 7.6) and homogenized twice for $3 \mathrm{~min}$ in a Stomacher 400 (Seward, London, UK) laboratory blender. The homogenate was transferred to sterile $50 \mathrm{ml}$ polypropylene tubes (Corning, NY, USA). Lysis buffer was added to bring the volume up to $45 \mathrm{ml}$. The samples were incubated horizontally in a water bath at $37^{\circ} \mathrm{C}$ and shaken at $200 \mathrm{rpm}$ for $30 \mathrm{~min}$. The samples were then centrifuged at $3220 \times \mathrm{g}$ for $30 \mathrm{~min}$ at room temperature. The pellet was re-suspended in $40 \mathrm{ml}$ washing buffer ( $0.35 \%$ Lutensol AO- 07 , and PBS) and incubated horizontally 
Table 1 Primer and probe sequences used in this study

\begin{tabular}{|c|c|c|}
\hline \multicolumn{2}{|c|}{ Salmonella enterica serovar Typhimurium: } & \multirow[t]{3}{*}{ Mann et al. (2013) } \\
\hline fimAF1 & 5'-ССТTTCTCCATCGTCCTGAA-3' & \\
\hline fimAR2 & 5'-TGGTGTTATCTGCCTGA-3' & \\
\hline FimAS1 & 5'-FAM-TGCGATCCGAAAGTGGCGG-BHQ1-3' & \multirow{5}{*}{ Rossmanith et al. (2006) } \\
\hline \multicolumn{2}{|c|}{ Listeria monocytogenes } & \\
\hline LIP1 & 5'-GATACAGAAACATCGGTTGGC-3' & \\
\hline LIP2 & 5'-GTGTAATCTTGATGCCATCAGG-3' & \\
\hline LIP probe 2 & 5'-FAM-CAGGATTAAAAGTTGACCGCA-MGB-3' & \\
\hline
\end{tabular}

in a water bath, shaken at $200 \mathrm{rpm}$ for $30 \mathrm{~min}$ at the temperatures used during the lysis step. Afterwards, the samples were centrifuged at $3220 \times g$ for $30 \mathrm{~min}$ at room temperature, and the supernatant was gently discarded. The pellet was resuspended in $500 \mu \mathrm{l}$ PBS, transferred to a $1.5-\mathrm{ml}$ plastic tube (Eppendorf, Hamburg, Germany), washed twice with $1 \mathrm{ml}$ PBS, and additional centrifugation for $5 \mathrm{~min}$ at $5000 \times \mathrm{g}$. The whole pellet was subsequently used for DNA extraction.

\section{Molecular Enrichment}

In contrast to the original Matrix-Lysis protocol, for ME samples, the DNA was eluted directly with two times $50 \mu \mathrm{l} 1 \times$ PCR buffer from the DNA extraction kit instead of $50 \mu \mathrm{l}$ of double distilled water. For the actual ME step, $22 \mu \mathrm{l}$ of the ME-Master mix was added to the $100 \mu$ l eluate, and the whole $122 \mu$ l were used for the pre-PCR which can be subsequently used for the actual qPCR detection (Fig. 1). The ME-Master mix contained all ingredients of the qPCR reactions (with the exception of the respective probes) to reach the following final concentrations: $3.5 \mathrm{mM} \mathrm{MgCl}_{2}, 500 \mathrm{nM}$ of each Primer (Table 1), $200 \mu \mathrm{M}$ dNTPs, and 1.5 U polymerase. The amount of ME-Master mix is solely dependent on the highest available concentration of the respective ingredients and could be reduced for future studies.

The pre-PCR thermoprofile was based on those of previously described qPCRs and was run for 10 cycles to obtain sufficient target amplification (Rossmanith et al. 2006; Mann et al. 2013). A pre-PCR temperature profile with an initial denaturation step at $94{ }^{\circ} \mathrm{C}$ for $2 \mathrm{~min}$ and an amplification protocol with 45 cycles $\left(94{ }^{\circ} \mathrm{C}\right.$ for $15 \mathrm{~s}, 64^{\circ} \mathrm{C}$ for $1 \mathrm{~min}$, $94{ }^{\circ} \mathrm{C}$ for $30 \mathrm{~s}$, and $60{ }^{\circ} \mathrm{C}$ for $1 \mathrm{~min}$ ) was used.

\section{Results and Discussion}

While molecular biological detection methods such as qPCR have been successfully adapted for quantification of pathogens from food, they still cannot compete with the traditional microbiological enrichment-based methods in terms of their LOD. Indeed, oftentimes, such methods are used after a primary enrichment step which usually takes between 20 and $24 \mathrm{~h}$ (Mester et al. 2017).
In order to evaluate if a ME approach could potentially lower the detection limit of PCR-based methods, first the approach itself had to be evaluated. Therefore, the LOD of two conventional qPCR assays for L. monocytogenes and $S$. enterica ser. Typhimurium and the respective ME-based qPCR approach targeting both pathogens simultaneously was determined directly from the dilution series in PBS.

For this purpose, triplicates of low pathogen inocula (between $\left.2.00 \times 10^{2}-1.00 \times 10^{0} \mathrm{CFU} / 100 \mu \mathrm{l}\right)$ of L. monocytogenes and $S$. enterica ser. Typhimurium were processed with the NucleoSpin®-tissue-kit and subsequently used either for "conventional" qPCR detection or for the ME-qPCR approach. The results presented in Table 2 demonstrate that the LOD for each pathogen could be lowered by more than one log.

For L. monocytogenes, the experimentally determined LOD with the ME-qPCR approach was $3.50 \times 10^{\circ} \mathrm{CFU} /$ $100 \mu \mathrm{l}$ input for DNA extraction compared with $8.95 \times$ $10^{1} \mathrm{CFU} / 100 \mu \mathrm{l}$ input for DNA extraction of the "conventional" qPCR. For S. enterica ser. Typhimurium, the respective values are $8 \times 10^{0}$ compared with $2.03 \times 10^{2} \mathrm{CFU} /$ $100 \mu \mathrm{l}$ input for DNA extraction (95\% confidence; Table 2 ). These results accord well with those obtained by WGA, with a lower LOD of the ME-based approach (Maheux et al. 2011b).

While the results obtained with pure bacterial cultures were already very promising, the question still remained if the MEqPCR approach could also work with real food samples that contain non-target bacterial or sample DNA background as well as possible inhibitors or sample remnants. In order to test the applicability of the ME-qPCR approach for the whole analytical chain, replicates of UHT milk were artificially contaminated with low levels of $L$. monocytogenes and S. enterica ser. Typhimurium (between $2.00 \times 10^{2}-2.00 \times 10^{0} \mathrm{CFU} /$ $12.5 \mathrm{ml}$ UHT milk). These UHT milk samples were then processed with the sample preparation method Matrix-Lysis and subsequently used for "conventional" qPCR detection or the ME-qPCR approach. In accordance to the previous experiment, the LOD at $95 \%$ of both detection approaches was determined, and the results are presented in Table 3.

The results obtained for the UHT milk samples concur with those of the previous experiment and demonstrate that the $\mathrm{ME}$ approach effectively lowers the LOD of Matrix-Lysis by about one log scale for both pathogens. The LOD of "conventional" 
a "Conventional" Matrix-Lysis qPCR based detection

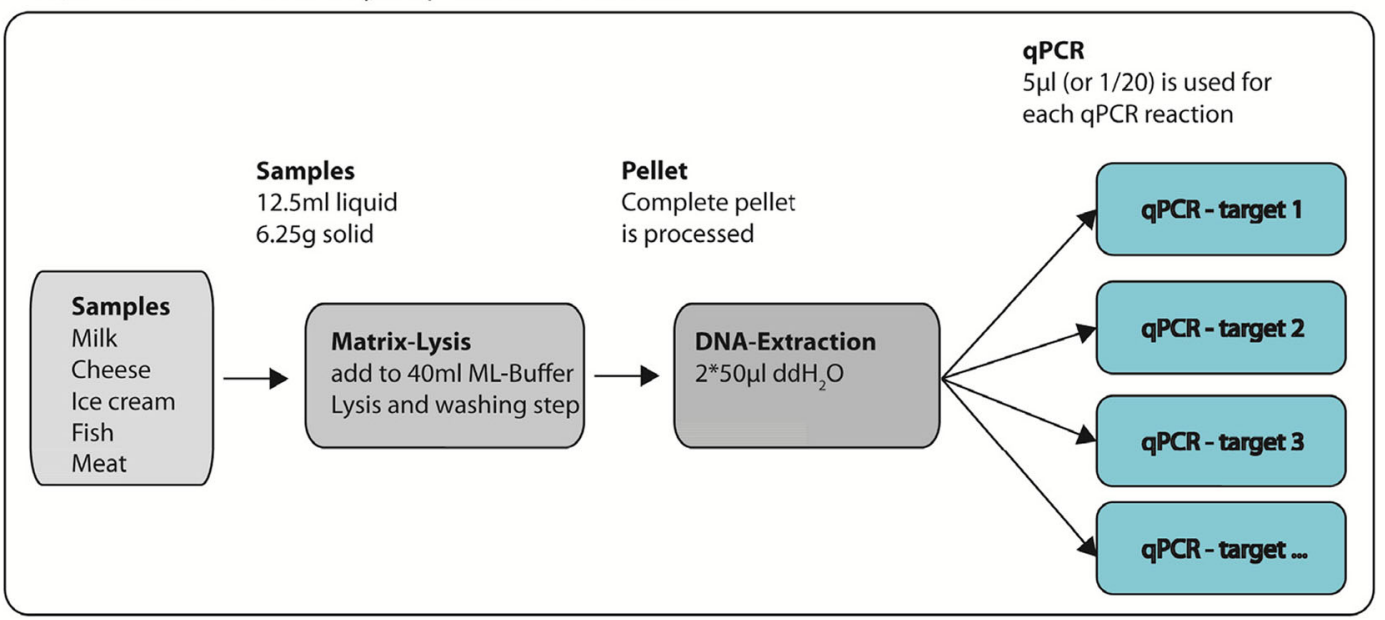

b ME-based Matrix-Lysis qPCR detection

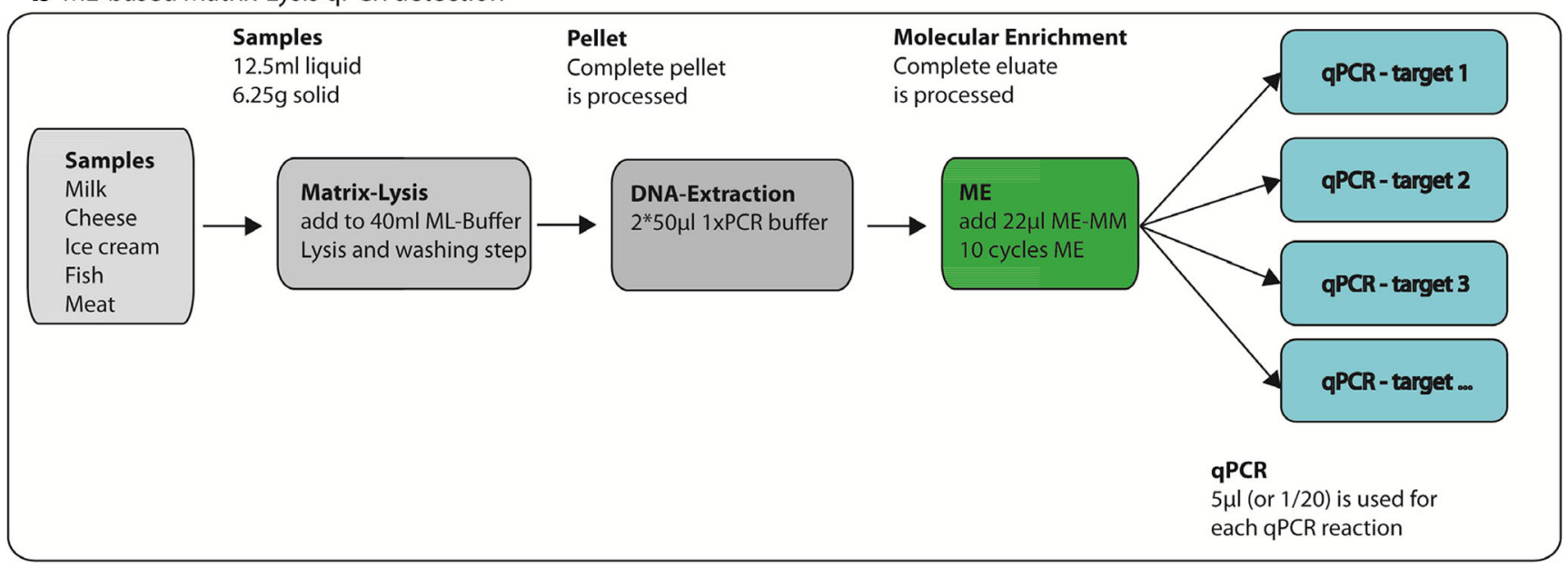

Fig. 1 Schematic workflow of the "conventional" Matrix-Lysis qPCR detection (a) and the proposed ME-based Matrix-Lysis qPCR detection (b)

Table 2 Comparative recovery and detection of L. monocytogenes and S. enterica ser. Typhimurium by "conventional” and ME-qPCR procedures from PBS without food matrix

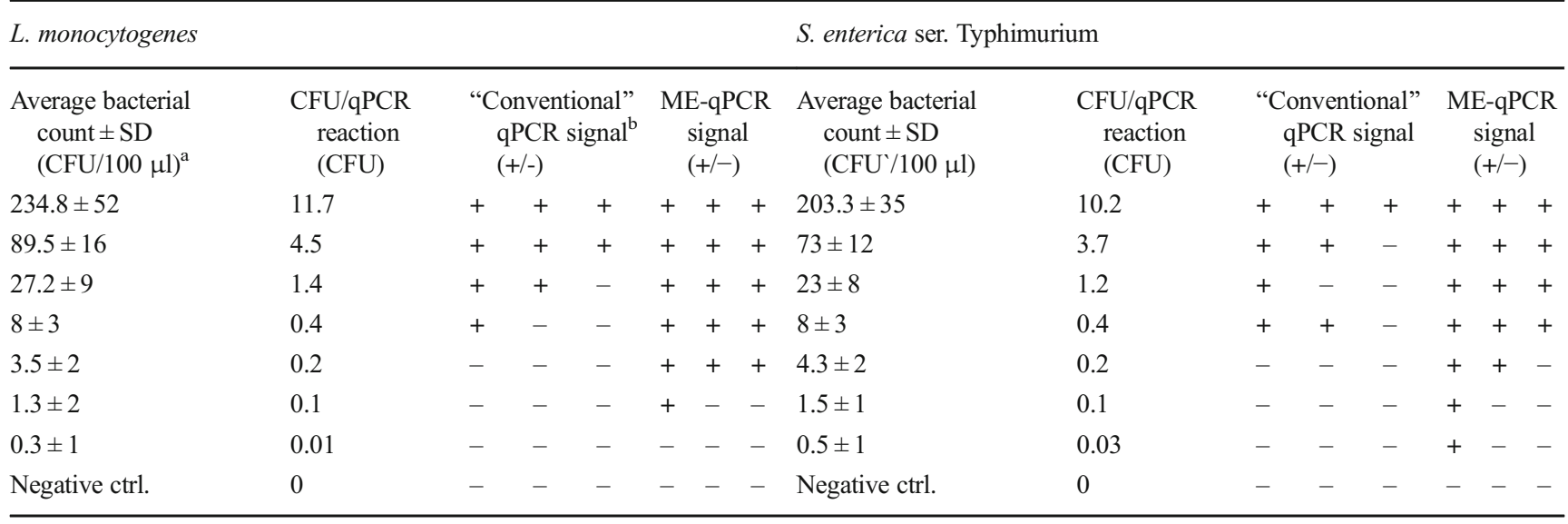

$C F U$, colony forming units; + Three of three replicates of the same sample showed a positive qPCR signal; - At least one of three replicates of the same sample showed a negative qPCR signal

${ }^{a}$ Number of CFU/100 $\mu$ l inoculated into $12.5 \mathrm{ml}$ UHT milk before Matrix-Lysis

${ }^{\mathrm{b}}$ Results of three independent experiments 
Table 3 Comparative recovery and simultaneous detection of L. monocytogenes and S. enterica ser. Typhimurium by "conventional" and ME-qPCR procedures from milk samples after Matrix-Lysis

\begin{tabular}{|c|c|c|c|c|c|}
\hline \multicolumn{3}{|l|}{ L. monocytogenes } & \multicolumn{3}{|l|}{ S. enterica ser. Typhimurium } \\
\hline $\begin{array}{l}\text { Average bacterial count } \pm \mathrm{SD} \\
\quad(\mathrm{CFU} / 12.5 \mathrm{ml})^{\mathrm{a}}\end{array}$ & $\begin{array}{l}\text { "Conventional" } \\
\text { qPCR signal } \\
\text { (+/-) after } \\
\text { Matrix-Lysis }\end{array}$ & $\begin{array}{l}\text { ME-qPCR signal } \\
(+/-) \text { after } \\
\text { Matrix-Lysis }\end{array}$ & $\begin{array}{l}\text { Average bacterial count } \pm \mathrm{SD} \\
\quad(\mathrm{CFU} / 12.5 \mathrm{ml})\end{array}$ & $\begin{array}{l}\text { "Conventional” } \\
\text { qPCR signal } \\
\text { (+/-) after } \\
\text { Matrix-Lysis }\end{array}$ & $\begin{array}{l}\text { ME-qPCR signal } \\
(+/-) \text { after } \\
\text { Matrix-Lysis }\end{array}$ \\
\hline $234.8 \pm 52$ & ++++++ & ++++++ & $203.3 \pm 35$ & ++++++ & ++++++ \\
\hline $89.5 \pm 16$ & +++++- & ++++++ & $73 \pm 12$ & +++++- & ++++++ \\
\hline $27.2 \pm 9$ & ++++-- & ++++++ & $23 \pm 8$ & ++++-- & ++++++ \\
\hline $8 \pm 3$ & +----- & +++++- & $8 \pm 3$ & ++---- & +++++- \\
\hline $3.5 \pm 2$ & +----- & ++++-- & $4.3 \pm 2$ & +----- & +----- \\
\hline $1.3 \pm 2$ & ------ & +----- & $1.5 \pm 1$ & ----- & +----- \\
\hline $0.3 \pm 1$ & ------ & +----- & $0.5 \pm 1$ & ----- & +----- \\
\hline Negative ctrl. & ------ & ------ & Negative ctrl. & ----- & ----- \\
\hline
\end{tabular}

CFU, colony forming units; + Three of three replicates of the same sample showed a positive qPCR signal; - At least one of three replicates of the same sample showed a negative qPCR signal

${ }^{a}$ Number of CFU/100 $\mu$ l inoculated into $12.5 \mathrm{ml}$ UHT milk before Matrix-Lysis

${ }^{\mathrm{b}}$ Results of six independent experiments

qPCR detection after Matrix-Lysis was determined to be about $2.00 \times 10^{2} \mathrm{CFU} / 12.5 \mathrm{ml}\left(1.60 \times 10^{1} \mathrm{CFU} / \mathrm{ml}\right) \mathrm{UHT}$ milk, which correlates with the previously published LOD of $1.00 \times 10^{1} \mathrm{CFU} / \mathrm{ml}$ (Mester et al. 2014). The application of a ME approach effectively lowers the LOD after Matrix-Lysis down to $2.00 \times 10^{1} \mathrm{CFU} / 12.5 \mathrm{ml}\left(1.60 \times 10^{0} \mathrm{CFU} / \mathrm{ml}\right)$ for both $L$. monocytogenes and $S$. enterica ser. Typhimurium (95\% confidence; Table 3). Although the obtained results demonstrate how the ME-qPCR approach can effectively improve the LOD of qPCR-based methods, they are still 1 log unit higher than those previously reported (Maheux et al. 2011b; Maheux et al. 2011a). One possible explanation could be that in this study the LOD was determined by comparison with a direct control and not by comparison with another quantification method, as was previously done (Maheux et al. 2011b; Maheux et al. 2011a). Based on the results of this study, it seems unlikely that the higher LOD was a result of the ME procedure used, as they had similar LODs without prior sample processing. While the WGA technique previously used was unspecific and thus nonselective with regard to the target organism, the applied pre-PCR technique used in this study only enriches the subsequent target, but it is likely to be more efficient with a high DNA background. It seems clear that both approaches have their merits, and it remains to be further demonstrated which approach will prove to be the most efficient and cost-effective for a defined sample type and target organism.

From the results obtained in this proof-of-principle study, it is also not completely clear yet if ME approaches can ultimately replace microbiological enrichments, which have a supposed LOD of one culturable bacterial cell per sample, but require longer incubation times and pathogen-specific enrichment media.
In conclusion, we have successfully demonstrated that a ME approach, as first described by Maheux et al. (2011), can also be applied to non-filterable food samples, if an efficient sample preparation step is used. The data presented in this study show that the LOD of an all-molecular pathogen detection approach from food can be effectively lowered by a factor of ten due to ME. The major advantages of such an approach are the reduced time to result and the possibility for simultaneous detection of different pathogens from the same sample. Although in this study only two pathogens were examined, in principle, the number of different subsequent detection reactions is unlimited, if an efficient ME is performed. However, before comparing such an allmolecular approach against the ISO standard methods, further development is necessary. In particular, the sample preparation method and the choice of ME step have to be adjusted toward different food classes. Nonetheless, the advantages of the overall approach appear to be worth the effort invested.

Acknowledgements The financial support by the Austrian Federal Ministry of Science, Research and Economy and the National Foundation of Research, Technology and Development is gratefully acknowledged.

Open access funding provided by University of Veterinary Medicine Vienna.

\section{Compliance with Ethical Standards}

Conflict of Interest Patrick Mester declares that he has no conflict of interest. Martin Wagner declares that he has no conflict of interest. Peter Rossmanith declares that he has no conflict of interest.

Ethical Approval This article does not contain any studies with human participants or animals performed by any of the authors.

Informed Consent Not applicable. 
Open Access This article is distributed under the terms of the Creative Commons Attribution 4.0 International License (http:// creativecommons.org/licenses/by/4.0/), which permits unrestricted use, distribution, and reproduction in any medium, provided you give appropriate credit to the original author(s) and the source, provide a link to the Creative Commons license, and indicate if changes were made.

\section{References}

Dwivedi HP, Jaykus LA (2011) Detection of pathogens in foods: the current state-of-the-art and future directions. Crit Rev Microbiol $37: 40-63$

European Commission (2005) Commission Regulation (EC) $N^{\circ} 2073 /$ 2005 of 15 November 2005 on microbiological criteria for foodstuffs. Off J Eur Union L338:1-26

Fernando MR, Chen K, Norton S, Krzyzanowski G, Bourne D, Hunsley B, Ryan WL, Bassett C (2010) A new methodology to preserve the original proportion and integrity of cell-free fetal DNA in maternal plasma during sample processing and storage. Prenat Diagn 30(5): 418-424. https://doi.org/10.1002/pd.2484

Jaykus LA (2003) Challenges to developing real-time methods to detect pathogens in foods. Asm News 69:341-347

Maheux AF, Bissonnette L, Boissinot M, Bernier JL, Huppe V, Berube E, Boudreau DK, Picard FJ, Huletsky A, Bergeron MG (2011a) Method for rapid and sensitive detection of Enterococcus sp. and Enterococcus faecalis/faecium cells in potable water samples. Water Res 45(6):2342-2354. https://doi.org/10.1016/j.watres.2011.01.019

Maheux AF, Bissonnette L, Boissinot M, Bernier JL, Huppe V, Picard FJ, Berube E, Bergeron MG (2011b) Rapid concentration and molecular enrichment approach for sensitive detection of Escherichia coli and Shigella species in potable water samples. Appl Environ Microbiol 77(17):6199-6207. https://doi.org/10.1128/AEM.02337-10

Mann E, Hein I, Mester P, Stessl B, Rossmanith P, Wagner M, Dzieciol M (2013) A robust and poisson validated quantitative $5^{\prime}$ nuclease TaqMan- real-time PCR assay targeting fimA for the rapid detection of Salmonella spp. in Food. Food Anal Methods 6(4):991-995. https://doi.org/10.1007/s12161-012-9534-Z

Mayrl E, Roeder B, Mester P, Wagner M, Rossmanith P (2009) Broad range evaluation of the matrix solubilization (matrix lysis) strategy for direct enumeration of foodborne pathogens by nucleic acids technologies. J Food Prot 72(6):1225-1233. https://doi.org/10. 4315/0362-028X-72.6.1225

Mester P, Wagner M, Rossmanith P (2010) Use of ionic liquid-based extraction for recovery of Salmonella typhimurium and Listeria monocytogenes from food matrices. J Food Prot 73(4):680-687. https://doi.org/10.4315/0362-028X-73.4.680

Mester P, Schoder D, Wagner M, Rossmanith P (2014) Rapid sample preparation for molecular biological food analysis based on magnesium chloride. Food Anal Methods 7(4):926-934. https://doi.org/10. 1007/s12161-013-9774-6

Mester P, Witte AK, Robben C, Streit E, Fister S, Schoder D, Rossmanith $P$ (2017) Optimization and evaluation of the qPCR-based pooling strategy DEP-pooling in dairy production for the detection of Listeria monocytogenes. Food Control 82:298-304. https://doi.org/ 10.1016/j.foodcont.2017.06.039

Nugen SR, Baeumner AJ (2008) Trends and opportunities in food pathogen detection. Anal Bioanal Chem 391(2):451-454. https://doi. org/10.1007/s00216-008-1886-2

Palka-Santini M, Cleven BE, Eichinger L, Kronke M, Krut O (2009) Large scale multiplex PCR improves pathogen detection by DNA microarrays. BMC Microbiol 9(1):1. https://doi.org/10.1186/14712180-9-1

Raghunathan A, Ferguson HR Jr, Bornarth CJ, Song W, Driscoll M, Lasken RS (2005) Genomic DNA amplification from a single bacterium. Appl Environ Microbiol 71(6):3342-3347. https://doi.org/ 10.1128/AEM.71.6.3342-3347.2005

Rossmanith P, Wagner M (2011) A novel Poisson distribution based approach for testing boundaries of real time PCR assays for food pathogen quantification. J Food Prot 74(9):1404-1412. https://doi. org/10.4315/0362-028X.JFP-10-458

Rossmanith P, Krassnig M, Wagner M, Hein I (2006) Detection of Listeria monocytogenes in food using a combined enrichment/realtime PCR method targeting the prfA gene. Res Microbiol 157(8): 763-771. https://doi.org/10.1016/j.resmic.2006.03.003

Stevens KA, Jaykus LA (2004) Bacterial separation and concentration from complex sample matrices: a review. Crit Rev Microbiol 30:7-24

Witte AK, Bobal M, David R, Blättler B, Schoder D, Rossmanith P (2017) Investigation of the potential of dry ice blasting for cleaning and disinfection in the food production environment. LWT-Food Sci Technol 75:735-741. https://doi.org/10.1016/j.lwt.2016.10.024 